\title{
Migrants in tropical bird communities: the balanced breeding limitation hypothesis
}

\author{
Matthew D. Johnson, Allan M. Strong and Thomas W. Sherry
}

Johnson, M. D., Strong, A. M. and Sherry, T. W. 2006. Migrants in tropical bird
communities: the balanced breeding limitation hypothesis. - J. Avian Biol. 37:229-237.

Explanations for the ecological integration of migratory and non-migratory (resident) insectivorous birds in the tropics have been complicated by the paradox that arthropod abundances are low when bird abundances reach their annual peak. The breeding currency hypothesis and the nest predation hypothesis both account for this paradox by postulating that residents are held below the non-breeding season carrying capacity, which frees resources available for migratory insectivores. The breeding currency hypothesis suggests residents are limited by food suitable for nestlings, whereas the nest predation hypothesis emphasizes the primacy of high rates of nest predation. However, theoretical arguments suggest that food availability and predation risk interact strongly to limit breeding birds. We use graphical analyses to extend the breeding currency hypothesis to incorporate effects of nest predation. This yields a more synthetic and realistic model for the integration of migrant and resident insectivores in the tropics the balanced breeding limitation hypothesis.

M. D. Johnson (correspondence), Department of Wildlife, Humboldt State University, Arcata, California, 95521 USA. A. M. Strong, Rubenstein School of Environment and Natural Resources, University of Vermont, 347 Aiken Center, Burlington, Vermont, 05405-0088 USA. T. W. Sherry, Department of Ecology and Evolutionary Biology, Tulane University, New Orleans, Louisiana,70118 USA. E-mail: mdj6@humboldt.edu

In temperate-tropical migratory systems, the autumn arrival of birds dramatically increases the number of birds in tropical habitats (Keast and Morton 1980; Fig. 1A). A classic ecological question concerning this system has been, how do tropical communities accommodate this influx of consumers given that winter food supply may be important in limiting bird densities (Willis 1966, Cox 1985, Ricklefs 1992, Greenberg 1995, Sherry et al. 2005)? This question is particularly intriguing for insectivorous migratory songbirds because their arrival in the tropics coincides with the late wet/early dry season and low arthropod abundance (Janzen and Schoener 1968, Janzen 1973, Buskirk and Buskirk 1976, Emlen 1980, Hespenheide 1980, Young 1994, Greenberg 1995, Strong and Sherry 2000, Kwok and Corlett 2002; see Fig. 1A and B). This resource paradox has led to a search for what limits bird abundances at various times of year in tropical ecosystems (Ricklefs 1992, Greenberg 1995, Martin 1996).

JOURNAL OF AVIAN BIOLOGY
Here, we briefly review two major hypotheses for the coexistence of insectivorous migrants in tropical bird communities - Greenberg's (1995) "breeding currency hypothesis" and ideas proposed by Hutto (1980) and Skutch $(1949,1985)$ that we collectively call the "nest predation hypothesis" - and we suggest that migrant to resident ratios in tropical habitats may be better understood by integrating these two hypotheses into a more synthetic model. First, we use theoretical arguments and resource-consumer graphical models to demonstrate how the breeding currency hypothesis operates in the context of a general resource-consumer model (Tilman 1982, Martin 1987, 1992, Grover 1997). Second, we incorporate into this model the effects of risk of nest predation on resident bird populations. Third, we discuss the assumptions and predictions of the resulting new model, which we call the balanced breeding limitation hypothesis. Our hope is that this analysis will encourage 

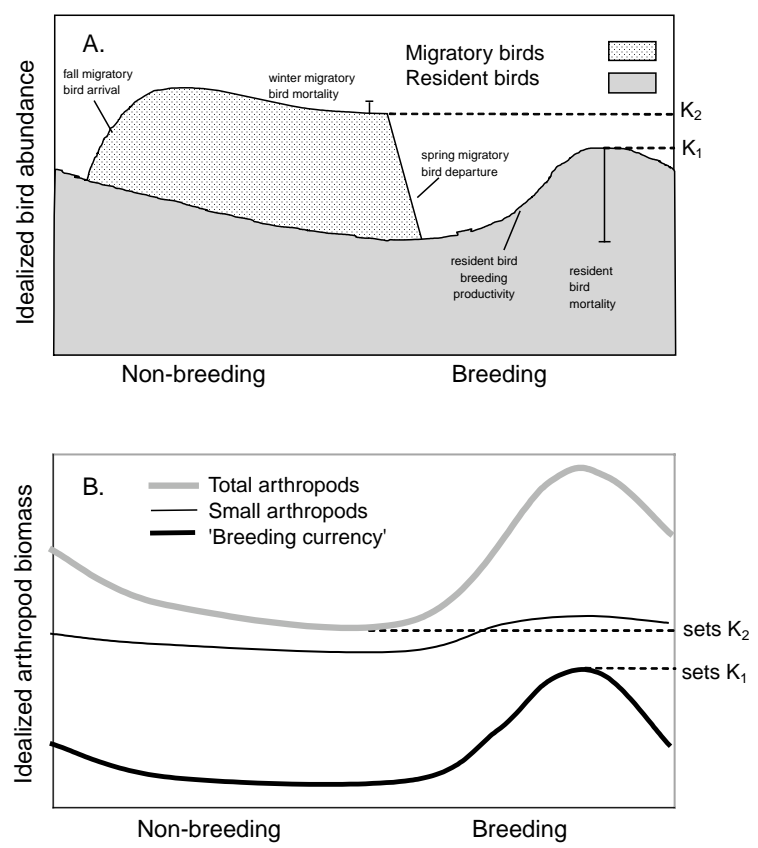

Fig. 1. (A) Idealized seasonal insectivorous bird abundance in the tropics, and the carrying capacities set by the available biomass of arthropods. Modified from Emlen (1980). (B) Idealized tropical arthropod seasonality and its hypothesized influence on tropical bird carrying capacities. The carrying capacity of breeding birds $\left(\mathrm{K}_{1}\right)$ is hypothesized to be a function of the availability of insects suitable as food for reproduction. This food, comprised of large, soft-bodied arthropods, is "breeding currency" and limits resident bird populations. The carrying capacity in the non-breeding season $\left(\mathrm{K}_{2}\right)$ is hypothesized to be a function of the availability of insects suitable for adult bird survival. This food, which includes both large and small insects, limits the total number of adult birds (residents and migrants combined) during the non-breeding season. The difference between $\mathrm{K}_{1}$ and $\mathrm{K}_{2}$ represents resources that residents cannot exploit and are, therefore, available to migrants.

additional work on the effects of food limitation and nest predation on tropical bird community composition.

\section{The breeding currency and nest predation hypotheses reviewed}

As a potential explanation for the coexistence of migratory and non-migratory (hereafter, "resident") birds in the tropics in the face of apparent resource shortages, Greenberg (1995) hypothesized that the productivity of breeding resident birds is a function of the abundance of large soft-bodied arthropods (i.e., breeding currency), which are needed as food for growing nestlings (Greenberg 1981; see $K_{1}$ in Fig. 1). The carrying capacity of adult insectivorous birds, in contrast, may be a function of the total year-long biomass of all arthropods, many of which are too small to be used as breeding currency (see $\mathrm{K}_{2}$ in Fig. 1). The result, according to the breeding currency hypothesis, is that there are two limits to bird abundance in the tropics: the first is lower and is set by the maximum availability of breeding currency; the second is higher and is set by the minimum biomass of arthropods available to sustain adult birds (Fig. 1B). The difference between the two represents resources that resident birds cannot exploit and are therefore available to migratory winter visitors. This hypothesis builds on previously proposed explanations of migrant to resident ratios in temperate regions, where seasonality is thought to play a central role by marked temporal variation in food supply (MacArthur 1959, Herrera 1978)

Recent field data provided some support for this hypothesis and some of its assumptions (Johnson et al. 2005). Among 19 field sites in Jamaica, the biomass of breeding currency was much more seasonal than that of small prey. Small prey dominated in the non-breeding season, while breeding currency was comparatively abundant in the breeding season, and the two arthropod groups were largely taxonomically distinct - two assumptions that must be true for the hypothesis to operate. As the hypothesis predicts, the ratio of large arthropod biomass during the breeding season to total biomass of arthropods during the non-breeding season was negatively correlated with the proportion of migrants among the sites. However, once the effects of the arthropod biomass ratio were statistically controlled, the proportion of migrants remained significantly higher in disturbed than in undisturbed sites, suggesting factors other than food limitation may also affect migrant to resident abundance ratios.

Numerous other researchers have found that migrant to resident abundance ratios are high in disturbed areas (see papers in Keast and Morton 1980, Hagan and Johnston 1992). This pattern is the basis for the second major hypothesis for the integration of insectivorous migrants and residents in the tropics. Hutto (1980) suggested that because human-disturbed habitats tend to be structurally simple (especially agricultural plantations for example), resident populations within them are kept low by the scarcity of safe nesting sites and high rates of nest predation. Residents tend to remain faithful to breeding sites year-round to ensure their repeated use, especially when nesting sites are limited and defensible (Alerstam and Enckell 1979, Greenberg and Gradwohl 1986, Switzer 1993, but see Levey and Stiles 1992). Therefore, according to the nest predation hypothesis, disturbed habitats may remain chronically under-used during the non-breeding season (Skutch 1949), permitting migratory birds to exploit the resulting vacancies and surplus of winter food.

Few data are available to evaluate the nest predation hypothesis. Evidence suggests that predation rates are high near habitat edges in the tropics (see review by Söderström 1999), although the effect is not as clear as 
in temperate forests (Laurance et al. 1993, Latta et al. 1995). Some studies have documented higher nest predation rates in disturbed and/or regenerating tropical habitats than in primary forests (Gibbs 1991, Burkey 1993, Cooper and Francis 1998, Wong et al. 1998), and this effect has generally been attributed to reduced structural complexity (Janzen 1978, Telleria and Diaz 1995), but other studies have failed to document consistent differences between forests and second growth woodlots, gardens, or forest remnants (Snow and Snow 1963, Skutch 1985, Laurance et al. 1993). Data from agricultural plantations are lacking. Nonetheless, higher rates of nest predation in human disturbed than in undisturbed sites are well documented in the temperate zone (e.g., Wilcove 1985, Robinson et al. 1995), making similar effects a reasonable supposition for tropical habitats as well (Martin 1996). Indeed, several researchers contend that evidence for higher overall nest predation rates in the tropics than in temperate forests could be an artifact of studying tropical birds in ubiquitous disturbed and/or fragmented habitats (Oniki 1979, Gibbs 1991, Sieving 1992). Clearly, additional studies of the relative impact of nest predation in different tropical habitats are needed, especially in heavily disturbed areas (e.g., agricultural plantations) versus large contiguous blocks of undisturbed tropical forests.

Other hypotheses exist for the integration of migrant and resident birds in the tropics (see Greenberg 1995 for review), some of which probably operate for particular migrant groups or in particular regions. The breeding currency and the nest predation hypotheses both invoke tropical seasonality and are therefore less likely to be important for migrants wintering near the equator, where seasonality is comparatively weak. Here, hypotheses suggesting that migrants track irregular/ephemeral foods or habitats are probably appropriate (Leisler 1992), especially for wandering frugivores (Willis 1966, Karr 1976, Alerstam and Enckell 1979, Waide 1980, Leck 1987). However, many wintering migrants remain locally resident, often territorial, and forage for small arthropods (Rappole 1995, Salewski et al. 2002), and the majority of migrants winters in the northern tropics, where seasonality is more pronounced (Moreau 1972, Keast and Morton 1980, Leisler 1992). The breeding currency and nest predation hypotheses are the only ones that adequately address migrant to resident ratios for territorial migrant insectivores. Here, we offer a theoretical basis for integrating these two hypotheses.

\section{Resource-consumer model for the breeding currency hypothesis}

Consider two groups of birds, migrants (mig) and residents (res), that rely on two resources, breeding currency (i.e., the biomass of large, soft-bodied arthropods in the breeding season; $b c$ ) and non-breeding season total arthropod biomass (nba; sensu Tilman 1982, Grover 1997). The zero net growth isocline (ZNGI) for each bird group is the one along which a group's growth rate equals its mortality rate (Fig. 2). "Growth" for resident birds is annual reproduction, for migrants it is the annual arrival and settlement into tropical habitats. For each ZNGI, the population density of the bird group will increase in habitats with resource availabilities that exceed these isoclines, i.e., lie outside the ZNGI, and will decrease where resource availabilities fall below the ZNGI. According to the breeding currency hypothesis, resident birds are limited much more strongly by the availability of breeding currency than by non-breeding season arthropods, as reflected by the shape of $\mathrm{ZNGI}_{\text {res }}$ in Fig. 2. Migrant birds are not directly affected by the availability of breeding currency and hence have a horizontal ZNGI illustrating the limiting effect of non-breeding season arthropods only (Fig. 2). This model application for two consumers competing for one shared and one unshared resource has been previously explored by Holm and Armstrong (1981) and Tilman (1982).

The consumption rate of these resources for each bird type is a vector $(C)$ made of two perpendicular components that are the products of the population density $(N)$ of each bird group and the per capita rate of consumption $(c)$ of each resource, so that

$C_{\text {res }}=N_{\text {res }} c_{\text {res:bc }}+N_{\text {res }} c_{\text {res:nba }}$

and

$C_{m i g}=N_{m i g} c_{m i g: b c}+N_{m i g} c_{m i g: n b a}$

The slopes of the consumption vectors are therefore

$\underline{c_{\text {mig:nba }}}$

$c_{\text {mig:bc }}$

and

$\underline{c_{\text {res:nba }}}$

$c_{\text {res:bc }}$

for migrants and residents, respectively (Fig. 2; only residents are shown for simplicity). If we assume that residents consume proportionately more of the resource that limits their own growth (breeding currency), then the slope of the consumption vector for residents is less than 1.0, drawn considerably so. This is likely because foraging rates are generally higher during the breeding season while birds are supplying not only their own needs but provisioning their offspring as well. This assumption must be true for the equilibrium point of migrant and resident coexistence to be stable, which is evident by the widespread coexistence of migrants and residents in the field. For wintering migrants, the per capita rate of breeding currency consumption is assumed to be near zero, which rests on the supported assumption 


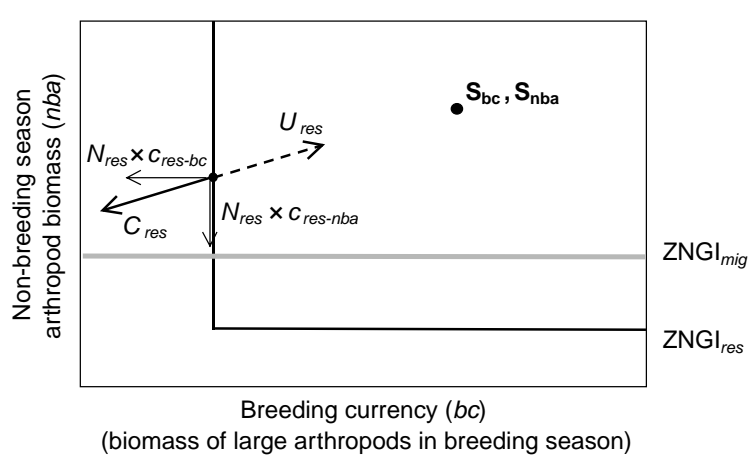

Fig. 2. Zero net growth isoclines (ZNGIs) for migrant (mig) and resident (res) tropical landbirds competing for two resources, non-breeding season arthropod biomass $(n b a)$ and the biomass of large arthropods in the breeding season, aka "breeding currency" $(b c)$. Resource consumption $(C)$ and supply $(U)$ vectors for resident birds and a given supply point $\left(S_{b c}, S_{n b a}\right)$ are also shown.

that small and large soft-bodied arthropods are reasonably taxonomically distinct (Greenberg 1995, Johnson et al. 2005). Therefore, $C_{m i g}$ is essentially vertical (i.e., migrant foraging depresses only non-breeding season arthropods).

The rate of supply (i.e., production) of resources in a habitat is also a vector $(U)$ made of two perpendicular components that are the supply rates of each resource (Fig. 2; only the combined supply vector is shown). The slope of the supply vector indicates the trajectory resource availability would take if consumption ceased. Thus, supply vector slopes vary among habitats that "support" different levels of arthropods (i.e., have different carrying capacities). An equilibrium outcome of a consumer-resource interaction is the point at which a locally stable equilibrium is achieved, where

$U+C=0$

which will occur when the resource supply vector is exactly opposite in direction and magnitude from the consumption vector (Tilman 1982). Graphically, this occurs at a point on the ZNGI where extension of the consumption vector points toward a supply point $\left(S_{b c}\right.$, $S_{n b a}$ ) that corresponds to the amount of breeding currency and non-breeding arthropod biomass a habitat would support in the absence of consumption (Fig. 2; Grover 1997). The length of the supply vector is directly proportional to the distance from the ZNGI to the supply point. Insect samples (i.e., measures of standing crop) provide an index of these supply points because migrants distribute among tropical habitats in direct proportion to food resources as measured by standing crop (Johnson and Sherry 2001, Sherry et al. 2005). Therefore, insect consumption rates approximately match productivity ("habitat matching" Fagan 1987), and insect populations thus stabilize in proportion to the supply point of each habitat (sensu Tilman 1982).
Combining migrants and residents (Fig. 3), a stable equilibrium point occurs at the intersection of their ZNGIs, and the outcome of competition between these groups of birds depends on the relative position of the supply point on the resource plane. Coexistence of migrants and residents occurs for supply points falling between the consumption vectors and outside the ZNGIs of each bird type (light gray area in Fig. 3). Widespread coexistence is a peculiarity of applying this model to consumers sharing only one of two modeled resources (Tilman 1982), and it is consistent with observation (in reality, the zones of a single bird group may be so narrow as to be non-existent in nature; Holm and Armstrong 1981). It is the variation of proportions of migrants and residents within the gray area of coexistence that is the focus of this analysis.

Consider four habitats within the region of coexistence, each with a different supply point, $A, B, C$, and $D$ (Fig. 3). Habitat $A$ has a relatively high availability of breeding currency and low availability of non-breeding season arthropod biomass. Therefore, according to the breeding currency hypothesis, it should have a relatively low proportion of migrants in the bird community. Habitats $B$ and $C$ should each support proportionately more migrants because they support more non-breeding season arthropod biomass and less breeding currency, respectively. Habitat $D$ should support the highest proportion of migrants. Thus, we see that the proportion of migrants in a bird community should, as Greenberg predicted, increase as the ratio of non-breeding season arthropod biomass to breeding currency increases (diagonal arrow in Fig. 3). This analysis of the breeding currency hypothesis identifies it as a special case of the more general "resource-ratio hypothesis" for the coexistence of competing consumers (Grover 1997), which has been applied primarily in limnological studies (Smith 1993, Sommer 1993).

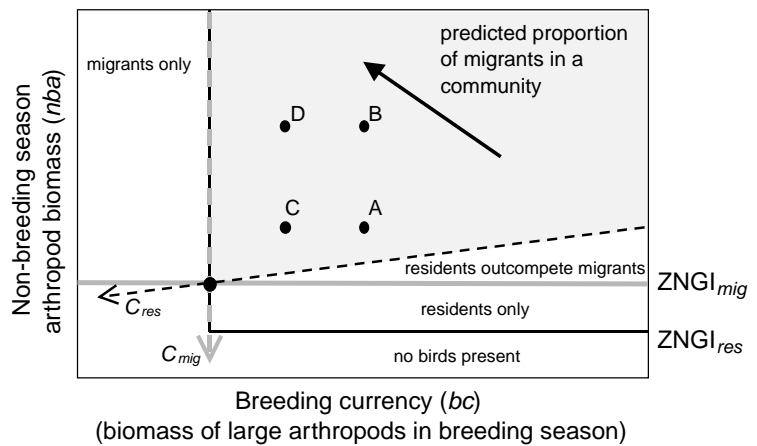

Fig. 3. Outcome of competition between migrant and resident birds along a 2-resource plane, showing the trend in migrant to resident ratios as predicted by the breeding currency hypothesis. Resource consumption vectors are shown for migrants and residents $\left(C_{m i g}\right.$ and $C_{\text {res }}$, respectively). Four hypothetical habitats within the region of coexistence, each with a different supply point, are also shown (A-D; see text for explanation of migrant to resident ratios in each). 


\section{Extending the breeding currency hypothesis to incorporate effects of nest predation}

A combined effect of food limitation and nest predation on bird populations is likely because food availability and nest predation act in concert to influence breeding birds (Skutch 1949, Martin 1992, 1995, Martin et al. 2000a,b; Fig. 4). For a constant clutch size, increases in foraging time lead to asymptotically higher nestling growth rates and food-influenced survival probabilities (dashed curve). Meanwhile, increases in foraging time also lead to higher nest predation probabilities (solid curves) because the concomitant increase in number of feeding trips attracts predators and reduces nest guarding time. Graphically, the optimal reproductive strategy is represented by the maximum difference between these curves (illustrated with vertical lines), and it is the time parents spend foraging that maximizes food-influenced survival (i.e., minimizes starvation) while minimizing the probability of nest predation. Increases in risk of nest predation that might occur, for example, in disturbed habitats act to shift the probability of nest predation curve to the left. For a given availability of breeding food, the resulting optimal strategy is one that carries not only a higher probability of nest predation $(a>b)$, but also a lower rate of food-influenced survival $(c<d$; Martin 1987, 1992; Fig. 4).

This analysis indicates that an increase in risk of nest predation lowers the probability of food-influenced survival for a given availability of breeding food. Therefore, to maintain zero net growth in the population,

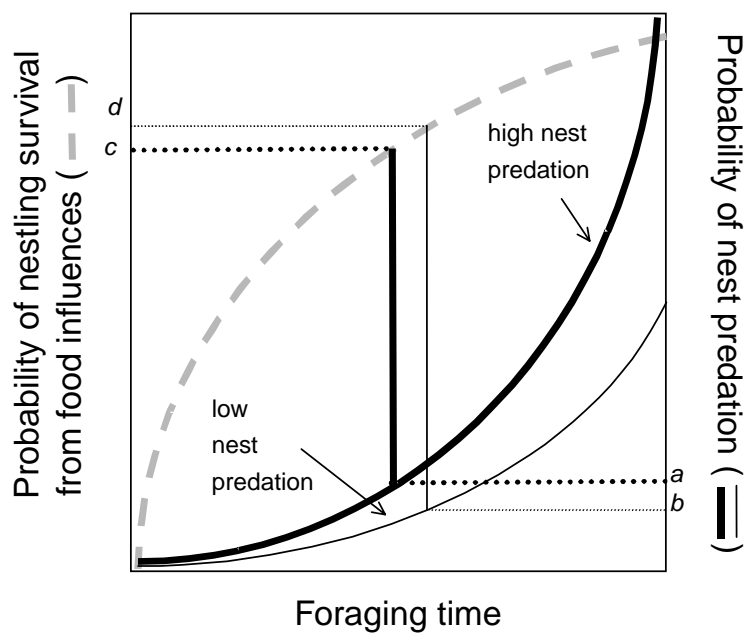

Fig. 4. Interactive effects of food availability and nest predation, mediated by foraging time, on the probability of nest predation (solid upward curves) and food provisioning (dashed curve) as modeled by Skutch (1949) and Martin (1992). Increases in risk of nest predation shift the probability of nest predation curve to the left (solid, heavy black line). For a given availability of breeding food, the resulting optimal strategy is one that carries not only a higher probability of nest predation $(a>b)$, but also a lower rate of food-influenced survival $(c<d)$. resident birds will require more breeding currency in sites with high than low risks of nest predation. This alters the shape of $\mathrm{ZNGI}_{r e s}$ in high predation risk sites by shifting the vertical portion of the ZNGI to the right, further "up" the breeding currency axis (Fig. 5).

The ramifications of this shift in the ZNGI can be seen most easily by examining the resulting change in resident population size for two hypothetical habitats, $Z$ and $Z^{\prime}$, characterized by the same resource supply point but with low and high risks of nest predation, respectively (Fig. 6). For habitat $Z$, we see the consumption and supply vectors $C$ and $U$ that result in an equilibrium outcome for resident birds, i.e., where the rate of consumption equals the rate of supply. Graphically, $C$ and $U$ must be equal in size, opposite each other, and pointed to/from the supply point, where the length of each is in proportion to the distance from the ZNGI to the supply point (Fig. 6A). For habitat $Z^{\prime}$, the ZNGI has been shifted right and is thus closer to the supply point. Consequently, the consumption and supply vectors that result in an equilibrium outcome for habitat $Z^{\prime}$ are shorter than for habitat $Z$ (Fig. 6B). Thus, the rate of resource consumption by residents must be slower for sites under high risk of nest predation. Mathematically,

$C_{r e s}^{\prime}<C_{r e s}$

where

$C_{r e s}=N_{\text {res }} \times c_{\text {res:bc }}+N_{\text {res }} \times c_{\text {res:nba }}$

Assuming per-capita rates of consumption in the highrisk habitat remain approximately equal $\left(c_{r e s}^{\prime} \approx c_{r e s}\right)$, the result is that $N_{r e s}^{\prime}<N_{r e s}$. In other words, resident populations will reach a lower equilibrium in sites with high risks of nest predation (Fig. 6C; i.e., $\mathrm{K}_{1}$ from Fig. 1). All else being equal, this will free non-breeding arthropod resources for winter visitors, and migrant to resident ratios will therefore be higher (than predicted by resources alone) in sites characterized by high risks of nest predation.

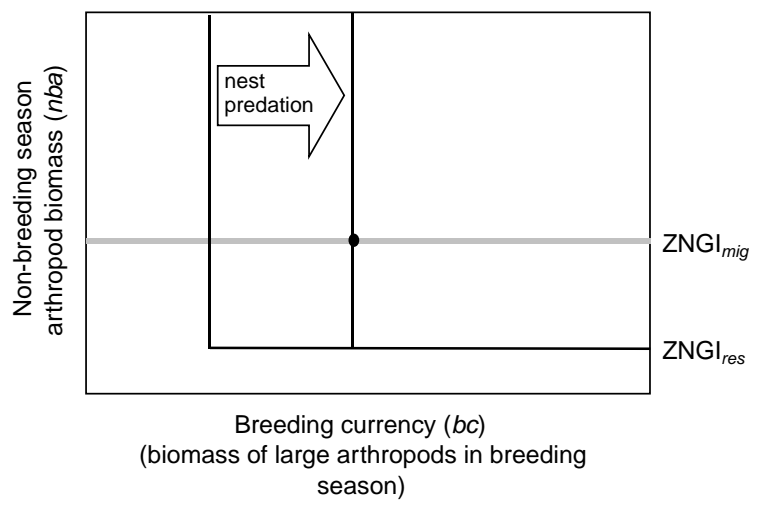

Fig. 5. Effect of increasing nest predation on the zero net growth isocline for resident birds. 

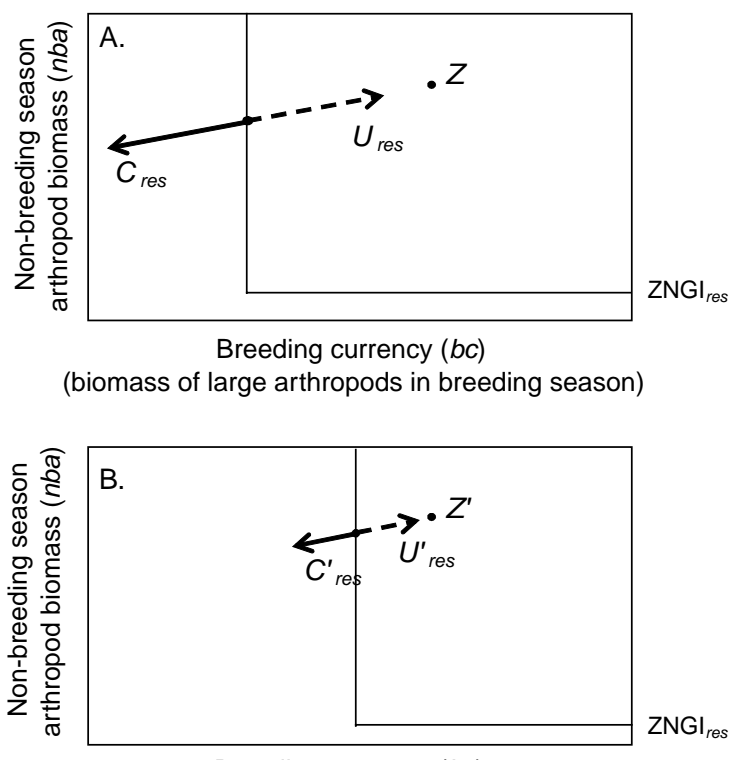

Breeding currency $(b c)$

(biomass of large arthropods in breeding season)

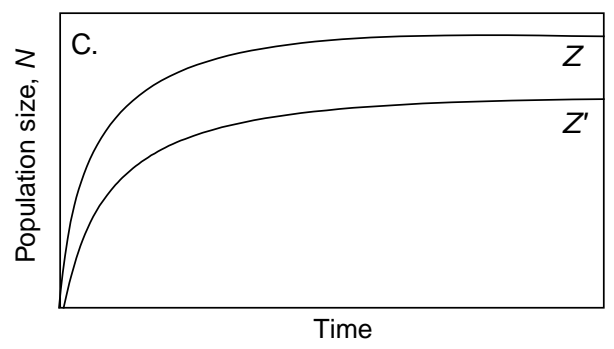

Fig. 6. Resource consumption and supply vectors for habitats with low (A) and high (B) risks of nest predation, and the resident bird population consequences thereof (C). Two hypothetical habitats, $Z$ and $Z^{\prime}$, characterized by the same resource supply point but with low and high risks of nest predation, respectively, are shown. See text for explanation.

\section{The balanced breeding limitation hypothesis}

Understanding that the availability of food and risk of nest predation interact to influence migrant to resident bird ratios in the tropics, we propose an extended model synthesizing elements of the breeding currency and nest predation hypotheses to explain the integration of migratory birds in tropical communities. The shared cornerstone of these two hypotheses is that residents are held below winter carrying capacity in a seasonal environment by breeding limitation (a seasonal bottleneck as first described by Ashmole 1963). This bottleneck allows a surplus of non-breeding (winter) foods available to other consumers such as migrants, a scenario perhaps more widespread among other groups of birds limited by conditions favoring breeding versus survival (Alerstam and Högstedt 1982). We hypothesize that the breeding productivity of tropical residents is limited by the interaction of nest predation probability and the availability of prey suitable for reproduction, whereas the combined abundance of migrants and residents during the non-breeding season is set by the availability of food suitable for adult survival. Thus, we predict that the proportion of migrants in a community is inversely correlated with the difference between these population limits. This can be envisioned most simply by noting that the proportion of migrants in habitats should be positively related to both the rate of nest predation and the ratio of non-breeding season arthropod biomass to breeding currency biomass (i.e., large, soft-bodied arthropods; Fig. 7). Note that in this model we switched the order of biomasses in the arthropod ratio from previous discussions to achieve a positive relationship. We call this model the "balanced breeding limitation hypothesis" because it invokes the limitation of breeding residents as a balance between the availability of breeding currency and risk of nest predation.

The primary prediction of the balanced breeding limitation hypothesis is that site-specific measures of breeding currency to non-breeding arthropod biomass ratios and rates of nest predation should better predict migrant to resident ratios than should arthropod biomass ratios alone. A second correlative prediction is that habitats with similar arthropod availabilities but different human disturbance regimes should have predictably different bird communities, with migrants disproportionately common in the most disturbed sites. These data are currently lacking. An experimental prediction of our hypothesis is that a reduction of nest predation (e.g., via predator trapping) should not only decrease the migrant to resident ratio of a site (via the nest predation hypothesis), but it should also increase the consumption of breeding currency. Use of bird exclosures may permit quantifying the change in insect biomass resulting from the cessation of bird predation. Thus, one would predict that consumption of breeding currency should be higher (i.e., a large difference in arthropod biomass inside and outside exclosures) in sites with lower rates of nest predation. Similar predictions can be made for experimental enhancements of nest predation. Note, however, that a change in nest predation rate does not guarantee a change in breeding productivity (Jones et al. 2005), because over long tropical breeding seasons birds may keep nesting until fledging some number of young. This propensity would erode the predicted links between manipulations of nest predation and migrant to resident abundance ratios.

Greenberg (1995) outlined and argued validity for the assumptions of the breeding currency hypothesis, and field data confirm some of his assertions (Johnson et al. 2005). With the addition of nest predation considerations in the balanced breeding limitation hypothesis, two additional assumptions must be noted. First, for a winter surplus of arthropods to develop in habitats where 
Fig. 7. "Balanced breeding limitation hypothesis" showing a hypothesized relationship between the rate of nest predation, ratio of total non-breeding season arthropod biomass to breeding currency biomass, and the proportion of migrants in a bird community.

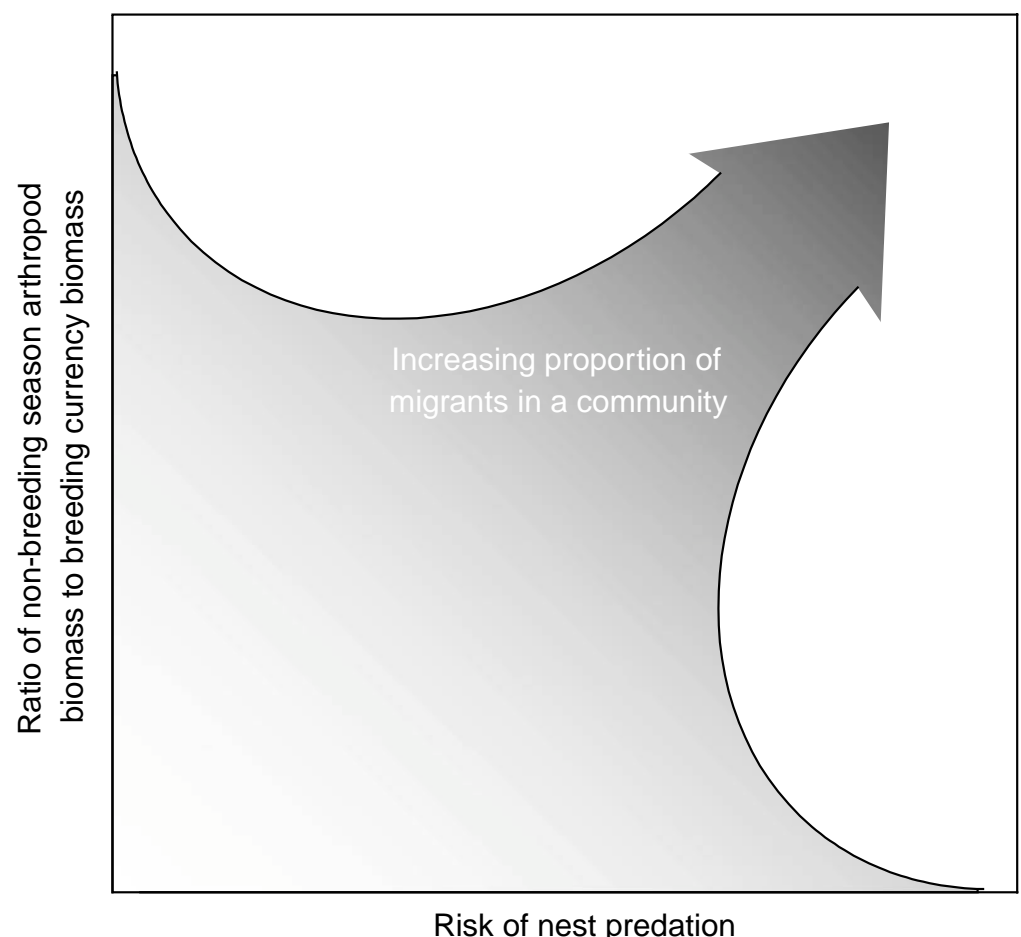

residents are limited by breeding food and risk of nest predation, resident birds must not shift among habitats between seasons. Seasonal site fidelity may confer evolutionary advantages on resident birds in the tropics, particularly when nest sites are limited (Switzer 1993), and evidence suggests that habitats little-used by residents remain so all year (Hutto 1980, Gochfield 1985). Indeed, some tropical residents defend year-long territories (Greenberg and Gradwohl 1986). However, some "resident" species do exhibit seasonal habitat shifts, including several in Jamaica (Lack and Lack 1972, MDJ, AMS unpubl. data, Leo Douglas pers. comm.). These species tend to be nectarivorous or frugivorous in the non-breeding season (Levey and Stiles 1992, Jahn et al. 2004). Therefore, these vagile species may switch from relying on large arthropods for breeding to frugivory during the non-breeding season. Indeed, seasonal dietary and habitat shifts may be intermediate points along a continuum of movement patterns from resident to migrant (Cox 1985, Levey and Stiles 1992). Nonetheless, seasonal movements among so-called residents remain inadequately understood, and could be common among some species or age classes.

This model, like many other treatments of migrantresident interactions, arouses the idea of competition between migrant and resident birds in the tropics, and suggests resident birds may be superior competitors (at least evolutionarily). Here, we provide some evidence in the context of our model to suggest at least the potential for interspecific competition between the two groups, but we leave the overwhelming task of analyzing residentmigrant competition to future researchers. Few have compared insectivorous migrant and resident diets in the tropics, and only Poulin and Lefebvre (1996), working in Panama, provided comprehensive data on prey sizes. They documented some partitioning between the two groups of birds in terms of prey taxa, and suggested that past competitive interactions were important in shaping migrants' contemporary diets. Important to the balanced breeding limitation hypothesis is their finding that there was considerable overlap in prey sizes within the birds' diets; $75 \%$ and $61 \%$ of all stomach samples in the non-breeding season were $<5 \mathrm{~mm}$ for migrants and residents, respectively (data calculated from their Table 1). Among our study sites in Jamaica, total bird abundance (migrant + resident) was positively correlated with total non-breeding season arthropod biomass and resident bird abundance was positively correlated with the availability of breeding currency (Johnson et al. 2005). Once effects of total arthropod abundance were statistically removed, migrant and resident abundances were inversely related (though not statistically so). These findings suggest there are shared limiting resources among migrants and residents in the non-breeding season, and their abundances at least partially compensate for each other. It should be noted, however, that on Caribbean islands most residents are large bodied and large-billed relative to the migrants (which are dominated by Parulidae, Lack 1987). Assessing whether these patterns occur in communities with more diverse 
migrant assemblages awaits future work in other locations. Martin et al. (2000a) provided compelling evidence that breeding birds in Argentina were not limited by food supply, though this study focused on factors governing clutch size and did not address migrant to resident ratios.

A final assumption of the balanced breeding limitation hypothesis arises from Skutch's (1949) hypothesized trade-off between parental foraging time and nest concealment (see Fig. 4). For increased food provisioning to lead to a greater chance of revealing a nest to predators, most nest predation must occur via diurnal predators, because most landbirds do not make feeding trips at night (Martin 1996). Diurnal birds are the most common nest predators on mammal-impoverished Caribbean islands (Latta et al. 1995, Woodworth 1997), but nocturnal mammalian and reptilian predation may be more important in other areas (Laurance et al. 1993, Wong et al. 1998). Nonetheless, Skutch's hypothesis that increased nest visitation leads to increased predation has recently received empirical support in both North and South America (Martin et al. 2000b). Additional work on nest predation and its effects on avian ecology is needed elsewhere in the tropics. Lastly, we have emphasized the effects of food, predation, and safe nest sites on bird population limitation, as have many before us (see review Newton 1998). However, recent work warns against overlooking effects of diseases and parasites (Loye and Zuk 1991). In particular, if host infestation rates differ among disturbed and non-disturbed habitats (see Latta 2003), then these factors may play a role in the integration of migrant and resident birds in the tropics.

Acknowledgements - T.L. George, R. Greenberg, G. Högstedt, R. Hutto, R. Ricklefs, T. Price, M. Mönkkönen, and an anonymous reviewer provided helpful comments on an earlier draft of this manuscript.

\section{References}

Alerstam, T. and Enckell, P. 1979. Unpredictable habitats and evolution of bird migration. - Oikos 33: 228-232.

Alerstam, T. and Högstedt, G. 1982. Bird migration and reproduction in relation to habitats for survival and breeding. - Ornis Scand. 13: 25-37.

Ashmole, N. P. 1963. The regulation of numbers of tropical oceanic birds. - Ibis 103: 458-473.

Burkey, T. V. 1993. Edge effects in seed and egg predation at two Neotropical rainforest sites. - Biol. Conserv. 66: 139-143.

Buskirk, R. E. and Buskirk, W. 1976. Changes in arthropod abundance in a highland Costa Rican forest. - Am. Midl. Nat. 95: 288-299.

Cooper, D. S. and Francis, C. M. 1998. Nest predation in a Malaysian lowland rain forest. - Biol. Conserv. 85: 199202.

Cox, G. 1985. The evolution of avian migration systems between temperate and tropical regions of the New World. - Am. Nat. 126: 451-474.

Emlen, J. 1980. Interactions of migrant and resident land birds in Florida and Bahaman pinelands. - In: Keast, A. E. and
Morton, E. S. (eds). Migrant birds in the Neotropics. Smithsonian Inst. Press, Washington, D.C., pp. 133-145.

Fagan, R. 1987. A generalized habitat matching rule. - Evol. Ecol. 1: 5-10

Gibbs, J. P. 1991. Avian nest predation in tropical wet forest: an experimental study. - Oikos 60: 155-161.

Gochfield, M. 1985. Numerical relationships between migrant and resident bird species in Jamaican woodlands. - Ornithol. Monogr. 36: 654-662.

Greenberg, R. 1981. Dissimilar bill size in tropical and temperate foliage gleaning birds. - Oecologia 49: 143-147.

Greenberg, R. 1995. Insectivorous migratory birds in tropical ecosystems: the breeding currency hypothesis. - J. Avian Biol. 26: 260-264.

Greenberg, R. and Gradwohl, J. 1986. Constant density and stable territoriality in some tropical insectivorous birds. - Oecologia 69: 618-625.

Grover, J. P. 1997. Resource competition. - Chapman and Hall, London.

Hagan, J. M. and Johnston, D. W. (eds). 1992. Ecology and conservation of Neotropical migrant landbirds. - Smithsonian Inst. Press, Washington, D.C.

Herrera, C. M. 1978. On the breeding distribution pattern of European migrant birds: MacArthur's theme reexamined. - Auk 95: 496-509.

Hespenheide, H. A. 1980. Bird community structure in two Panama forests: residents, migrants, and seasonality during the non-breeding season. - In: Keast, A. E. and Morton, E. S. (eds). Migrant birds in the Neotropics. Smithsonian Inst. Press, Washington, D.C., pp. 227-238.

Holm, N. P. and Armstrong, D. 1981. Role of nutrient limitation and competition in controlling populations of Asterionella formosa and Microcystis aeruginosa in semi-continuous culture. - Limnol. Oceanogr. 26: 622-635.

Hutto, R. L. 1980. Winter habitat distribution of migratory land birds in western Mexico, with special reference to small, foliage-gleaning insectivores. - In: Keast, A. E. and Morton, E. S. (eds). Migrant birds in the Neotropics. Smithsonian Inst. Press, Washington, D.C., pp. 181-203.

Jahn, A. E., Levey, D. J. and K. G. Smith. Reflections across the hemispheres: a system-wide approach to New World migration. - Auk 121: 1005-10013.

Janzen, D. H. 1973. Sweep samples of tropical foliage insects: effects of seasons, vegetation types, elevation, time of day, and insularity. - Ecology 54: 687-708.

Janzen, D. H. 1978. Predation intensity on eggs on the ground in two Costa Rican forests. - Am. Midl. Nat. 100: 467-470.

Janzen, D. H. and Schoener, T. W. 1968. Differences in insect abundance and diversity between wetter and drier sites during a tropical dry season. - Ecology 49: 96-110.

Johnson, M. D. and Sherry, T. W. 2001. Effects of food availability on the distribution of migratory warblers on habitats in Jamaica. - J. Animal Ecol. 70: 546-560.

Johnson, M. D., Sherry, T. W., Strong, A. M. and Medori, A. 2005. Migrants in Neotropical bird communities: An assessment of the breeding currency hypothesis. - J. Animal Ecol. 74: 333-341.

Jones, J., Doran, P. J., Nagy, L. R. and Holmes, R. T. 2005. Relationship between Mayfield nest survival estimates and seasonal fecundity: a cautionary note. - Auk 122: 306-312.

Karr, J. R. 1976. On the relative abundance of migrants from the North American temperate zone in tropical habitats. - Wilson Bull. 88: 433-458.

Keast, A. E. and Morton, E. S. (eds). 1980. Migrant birds in the Neotropics. - Smithsonian Inst. Press., Washington, D.C.

Kwok, H. K and Corlett, R. T. 2000. The bird communities of a natural secondary forest and a Lophostemon confertus plantation in Hong Kong, South China. - Forest Ecol. Manage. 130: 227-234.

Kwok, H. K and Corlett, R. T. 2002. Seasonality of forest invertebrates in Hong Kong, South China. - J. Tropical Ecol. 18: 637-644. 
Lack, D. and Lack, P. 1972. Wintering warblers in Jamaica. - Living Bird 11: 129-153.

Latta, S. C. 2003. Effects of scaley-leg mite infestations on body condition and site fidelity of migratory warblers in the Dominican Republic. - Auk 120: 730-743.

Latta, S. C., Wunderle, Jr., J. M., Terranova, E. and Pagan, M. 1995. An experimental study of nest predation in a subtropical wet forest following hurricane disturbance. - Wilson Bull. 107: 590-602.

Laurance, W. F., Garesche, J. and Payne, C. W. 1993. Avian nest predation in modified and natural habitats in tropical Queensland: an experimental study. - Austral. Wildl. Res. 20: $711-723$.

Leck, C. F. 1987. Habitat selection in migrant birds: seductive fruits. - Trends Ecol. Evol. 2: 33.

Leisler, B. 1992. Habitat selection and coexistence of migrants and Afrotropical residents. - Ibis (Suppl.) 134: 77-82.

Levey, D. J. and Stiles, F. G. 1992. Evolutionary precursors of long-distance migration: resource availability and movement patterns in Neotropical landbirds. - Am. Nat. 140: 447476.

Loye, J. E. and Zuk, M. (eds). 1991. Bird-parasite interactions: ecology, evolution, and behavior. - Oxford, Univ. Press, Oxford.

MacArthur, R. H. 1959. On the breeding distribution pattern of North American migrant birds. - Auk 76: 318-325.

Martin, T. E. 1987. Food as a limit on breeding birds: a life history perspective. - Ann. Rev. Ecol. Syst. 18: 453-487.

Martin, T. E. 1992. Interaction of nest predation and food limitation in reproductive strategies. - Curr. Ornith. 9: 163197.

Martin, T. E. 1995. Avian life history evolution in relation to nest sites, nest predation and food. - Ecol. Monogr. 65: $101-127$.

Martin, T. E. 1996. Life history evolution in tropical and south temperate birds: what do we really know? - J. Avian Biol. 27: $263-272$

Martin, T. E., Martin, P. R., Olson, C. R., Heidinger, B. J. and Fontaine, J.J. 2000a. Parental care and clutch sizes in North and South American birds. - Science 287: 1482-1485.

Martin, T. E., Scott, J. and Menge, C. 2000b. Nest predation increases with parental activity: separating nest site and parental activity effects. - Proc. R. Soc. B 267: 2287-2293.

Moreau, R. E. 1972. The Palaearctic-African bird migration systems. - Academic Press, London.

Oniki, Y. 1979. Is nesting success low in the tropics? - Biotropica 11: 60-69.

Rappole, J. H. 1995. The ecology of migrant birds. - Smithsonian Inst. Press, Washington, D.C..

Ricklefs, R. E. 1992. The megapopulation: a model of demographic coupling between migrant and resident landbird populations. - In: Hagan, J. M., III and Johnston, D. W. (eds). Ecology and conservation of Neotropical migrant landbirds. Smithsonian Inst. Press, Washington, D.C., pp. $537-548$.

Robinson, S. K., Thompson, F. R. III, Donovan, T. M., Whitehead, D. R. and Faaborg, J. 1995. Regional forest fragmentation and the nesting success of migratory birds. - Science 267: 1987-1990.

Salewski, V., Bairlein, F. and Leisler, B. 2002. Different wintering strategies of two Palearctic migrants in West
Africa - a consequence of foraging strategies? - Ibis 144: $85-93$.

Sherry, T. W., Johnson, M. D. and Strong, A. M. 2005. Does winter food limit populations of migratory birds? - In: Greenberg, R and Marra, P. P. (eds). Birds of two worlds: Ecology and Evolution of migratory birds. Johns Hopkins University Press, Baltimore, Maryland, pp. 414-425.

Sieving, K. E. 1992. Nest predation and differential insular extinction among selected forest birds of Central Panama. - Ecology 73: 2310-2328.

Skutch, A. F. 1949. Do tropical birds rear as many young as they can nourish? - Ibis 91: 430-455.

Skutch, A. F. 1985. Clutch size, nesting success, and predation on nests of Neotropical birds, reviewed. - Ornithol. Monogr. 36: 575-594.

Smith, V. H. 1993. Applicability of resource-ratio theory to microbial ecology. - Limnol. Oceanogr. 38: 239-249.

Snow, D. W. and Snow, B. K. 1963. Breeding and the annual cycle in three Trinidad thrushes. - Wilson Bull. 75: 27-41.

Söderström, B. 1999. Artificial nest predation rates in tropical and temperate forests: A review of the effects of edge and nest site. - Ecography 22: 455-463.

Sommer, U. 1993. Phytoplankton competition in Pluss-sea: a field test of the resource-ratio hypothesis. - Limnol. Oceanogr. 38: 838-845.

Strong, A. M. and Sherry, T. W. 2000. Habitat-specific effects of food abundance on the condition of Ovenbirds wintering in Jamaica. - J. Animal Ecol. 69: 883-895.

Switzer, P. V. 1993. Site fidelity in predictable and unpredictable habitats. - Evol. Ecol. 7: 533-555.

Telleria, J. L. and Diaz., M. 1995. Avian nest predation in a large natural gap of the Amazonian rainforest. - J. Field Ornithol. 66: 343-351.

Thiollay, J. M. 1988. Comparative foraging success of insectivorous birds in tropical and temperate forests: ecological implications. - Oikos 53: 17-30.

Tilman, D. 1982. Resource competition and community structure. - Princeton University Press, Princeton, New Jersey.

Waide, R. 1980. Resource partitioning between migrant and resident birds: the use of irregular resources. - In: Keast, A. E. and Morton, E. S. (eds). Migrant birds in the Neotropics. Smithsonian Inst. Press, Washington, D.C., pp. 337-352.

Wilcove, D. S. 1985. Nest predation in forest tracts and the decline of migratory songbirds. - Ecology 66: 1211-1214.

Willis, E. O. 1966. The role of migrant birds at swarms of army ants. - Living Bird 5: 187-231.

Wong, T. C. M., Sodhi, N. S. O. and Turner, I. M. 1998. Artificial nest and seed predation experiments in tropical lowland rainforest remnants of Singapore. - Biol. Conserv. 85: $97-104$.

Woodworth, B. L. 1997. Brood parasitism, nest predation, and season-long reproductive success of a tropical island endemic. - Condor 99: 605-621.

Young, B. E. 1994. The effects of food, nest predation, and weather on the timing of breeding in tropical house wrens. - Condor 96: 341-353.

(Received 3 January 2005, revised 8 April 2005, accepted 13 April 2005.) 